\title{
Understanding Key-Informant Experiences and Perceptions of the 2016 Drought and Wildfires in Western North Carolina
}

\author{
Lauren M. Andersen, Abie N. Bonevac, Laura K. Thompson, Kara E. Dempsey, \\ ELIZABETH D. SHAY, AND MARGARET M. SUgG \\ Department of Geography and Planning, Appalachian State University, Boone, North Carolina
}

(Manuscript received 6 June 2018, in final form 23 October 2018)

\begin{abstract}
In 2016, an exceptional drought and subsequent wildfires devastated the southeastern United States. Western North Carolina (WNC), a socioeconomically growing region that is dependent on revenue from tourism and agriculture, was particularly impacted by the events. The Southeast is not typically considered to be water vulnerable, and few studies have explored drought and wildfire in WNC. However, the region is projected to experience elevated water vulnerability as a result of rapid population growth and increased climatic variability. The recent events highlight the need for better understanding of water-related experiences and perceptions to inform proactive policies for risk mitigation in WNC. To evaluate stakeholder experiences and perceptions relating to the events in 2016, the authors conducted telephone interviews with key informants from a variety of sectors in two counties (Buncombe and Watauga) and then subjected their responses to content analysis. Informants frequently discussed themes relating to the "Natural Resources and Environment" code group, with responses revealing concerns about the health effects of smoke exposure, as well as water quantity. Other common topics of discussion for informants include water management, public awareness, and disaster severity. The prevalence of other themes varied by county, demonstrating the importance of local context. Surprisingly, informants rarely discussed risk in the context of increasing population and development, suggesting that current policies may inadequately address future risks. Stakeholders across all sectors placed substantial emphasis on information dissemination both within agencies and to the public. With a better understanding of key-informant experiences and perceptions, policymakers will be better equipped to address policy shortcomings as well as to prepare for future hazards.
\end{abstract}

\section{Introduction}

In 2016, an exceptional drought and subsequent wildfires across the southeastern United States affected agricultural yields, tourism revenue, public health, and water resources in western North Carolina. The drought began in March 2016 and peaked in November 2016 (NCEI 2017). A combination of extremely dry conditions and complex mountain landscapes supported an unprecedented wildfire outbreak throughout October and November of 2016. In March of 2017, precipitation events finally brought relief to western North Carolina. Throughout the year-long drought, agricultural yields were reduced across the Southeast, including in western North Carolina. Though tourism revenue increased during the drought due to drier, sunnier days, the wildfires drove tourists away from the region. As the wildfires burned, smoke dispersed across the region and aggravated

\footnotetext{
Corresponding author: Elizabeth Shay, shayed@appstate.edu
}

respiratory distress in vulnerable populations. Dry conditions resulted in significantly lower stream discharges and slight changes to reservoir and groundwater levels, as well as complicated fire management (Konrad and Knox 2017).

Drought is the second most expensive and deadly natural disaster worldwide (NCEI 2018b). Drought has a slower onset than most extreme events, which can make the effects less tangible. Additionally, the effects of drought can be meteorological, hydrological, agricultural, and socioeconomic, further complicating studies of drought perceptions (NCEI 2018a). Western North Carolina is a complex, yet understudied region in hazards literature. In addition to drought, the region is subject to flooding, landslides, hurricanes, and winter storms. To date, few studies have explored water-related issues and climate change in the region. While severe droughts have occurred in the region in the past, it has not typically been considered water vulnerable. Instead, many existing studies into water vulnerability have 
focused on the western United States. Southern Appalachia's water resources are particularly vulnerable due to their sensitivity to changes in temperature and precipitation (Frei et al. 2002). In the future, climatic events are expected to become more variable, increasing the risk of drought and wildfire (IPCC 2013). The events in 2016 provide an opportunity to gain a better understanding of stakeholder perceptions of water-related vulnerability and inform efforts to mitigate the negative impacts of drought and wildfire in the future. With this knowledge, policies can be enacted to proactively anticipate and manage the risks of water-related hazards.

\section{a. Public perceptions}

Better understanding of public perceptions about drought may contribute to informed scientific and policy discussions and support sound decision-making and planning. The relationship between personal experience and perceived risk of water-related climatological events, including floods, droughts, and wildfires, is well established (Brody et al. 2008; Diggs 1991; Hamilton and Keim 2009; Spence et al. 2011; Woudenberg et al. 2008). Individuals who experience these events firsthand express less uncertainty about climate change and greater propensity for hazard mitigation. Several studies have explored the impact of drought on farmers and demonstrated how drought experience influences drought perception in agricultural communities (Diggs 1991; Saarinen 1966; Taylor et al. 1988; Woudenberg et al. 2008). This suggests that heightened perceptions related to hazardous climatological events can lead to greater agency among individuals.

Additionally, spatial location influences perceptions of climate change in the United States. A study of rural areas in nine states found regional variation in perceptions of climate change that were linked to regional climate, specifically snow-heavy regions experiencing reduced snowfall (Hamilton and Keim 2009). Brody et al. (2008) compared perceived climate change risk over space with actual experienced regional climate variation. A heightened sense of climate change was observed among individuals within close proximity to risk, such as those living on the coast. However, these perceptions were limited to widely publicized risks of climate change; other physical risks, such as living in a floodplain, did not affect perceptions (Brody et al. 2008). This suggests a need for region-specific approaches to climate change education. Furthermore, individual characteristics, including social, economic, demographic, and ideological variables, significantly influence perceptions of climate change, highlighting the importance of considering location (Brody et al. 2008; Hamilton and Keim 2009).

Knowledge of how the public is likely to respond to climatic impacts or initiatives is crucial because public responses can attenuate or amplify drought impacts. In the United States, studies exploring perceptions of drought normally focus on the arid and semiarid lands of the Great Plains and West, regions traditionally considered water vulnerable (Seager et al. 2009; Diggs 1991; Taylor et al. 1988; Woudenberg et al. 2008). However, recent droughts in the southeastern United States, although shorter than the multiyear droughts common in the western United States, have also had devastating consequences. In the coming years, water vulnerability in the Southeast will be exacerbated by climate change and population growth (Vörösmarty et al. 2000). The recent intensification of droughts can be attributed to climate change, which can increase the severity and frequency of hydrologic extremes (USGCRP 2016). This variability is particularly pronounced in mountainous regions, like western North Carolina. For example, Buncombe County receives an average annual precipitation of $40 \mathrm{in}$. $(1 \mathrm{in} .=2.54 \mathrm{~cm})$, whereas the neighboring Transylvania County receives $100 \mathrm{in}$. (PRISM Climate Group 2018). An additional stressor is the growing population, driven predominately by in-migration (Seager et al. 2009). Counties in western North Carolina have seen population growth as high as $22 \%$ over the last decade, outpacing the national average of $10 \%$ (U.S. Census Bureau 2000, 2010).

In public polls, water quality consistently ranks higher in public concern than water quantity or supply, even for those residing in arid climates (Cockerill 2010; Responsive Management 2003). Recent accounts of unsafe tap water due to failures of water treatment and infrastructure systems in American cities, such as Flint, Michigan, are raising alarm concerning the scientific basis for the current national drinking water standards. Studies consistently find policymakers' actions reflect public preferences and prioritize water quality in the public policy arena (Burstein 2010). Despite the lack of public attention and policydriven research, water quantity is a serious national concern. After adjusting for current water use and future changes in population growth and energy consumption, a recent study demonstrated the water supply in 7 of every 10 American counties may experience some climate change-related risk by the midcentury (Roy et al. 2012). Water quantity will become even more salient in the context of climate-driven changes in the provision of water extending to areas of the country that have not typically dealt with water-related stressors (O'Gorman and Schneider 2009).

\section{b. Decision-maker perceptions}

In western North Carolina, similar trends are found among decision-makers, who express little concern about water quantity (Cockerill 2014). Southern Appalachia is 
not typically considered to be a water-vulnerable region, and some models even project the region to experience increased water availability in the future (Manabe et al. 2004). Historically, water managers in western North Carolina have acquired new water sources as demand outgrew supply, and citizens have rarely experienced the effects of water quantity issues firsthand. However, in the context of climate change and population growth, new supplies may not be readily available in the future. Daily withdrawals of water in this region total 1724 million gallons, with an estimated $86 \%$ of this withdrawal used in aquaculture and cooling of power plants (Kenny et al. 2009). Furthermore, much of the water supply is provided by reservoirs and impoundments that generate hydroelectric power. Statewide, only $4.3 \%$ of North Carolina's energy comes from hydropower, slightly less than the national average. However, power generation potential is much higher in the mountain region with its distinctive topographical features. Recent droughts, like the event in 2017, have demonstrated how drought can emerge quickly, even after record-breaking wet periods, resulting in extremely dry conditions (e.g., $78 \%$ of North Carolina classified as D4 or "exceptional drought").

Specific sectors, such as water management, perceive water supply as a human capacity issue related to the growing population rather than a physical issue of decreasing precipitation and climate change (Cockerill 2014; Dow et al. 2007). Indeed, Dow et al. (2007) found that water system managers were most concerned about water quality and financial challenges, as compared with water quantity. Concerns about future drought impacts were noted only when drought managers had previous drought experience.

Findings from a local assessment of decision-maker perceptions of water quantity in western North Carolina suggested that decision-makers rarely use scientific data to make water management decisions (Cockerill 2014). Additionally, there was little concern about water quantity among decision-makers, with only half of the decision-makers surveyed reporting being "very concerned" about the reduction of their water supply by drought. At the county scale, there may be a "lack of resources, information, and political will" among officials regarding climate adaptation planning and implementation, similar to findings in other mountain communities (Archie 2014). This suggests that present adaptation and mitigation policies may inadequately address the risk of increased water vulnerability. As climate and water regimes change, water managers in western North Carolina may not be able to continue to rely on acquiring new sources when demand outgrows supply, and alternative solutions may be necessary
(Cockerill 2014). Understanding current local management practices and perceptions may help facilitate preparation for the future.

The 2016 events offer an opportunity to gauge stakeholder perceptions of water vulnerability in western North Carolina, which could inform policies to mitigate the impacts of climate change on water resources. The objective of the present study was to determine, How did key informants from two communities in western North Carolina perceive and respond to the drought and wildfire events of 2016? To answer this question, telephone interviews were conducted with stakeholders from Watauga and Buncombe Counties in the spring and summer of 2017. This study is part of an ongoing effort to develop a knowledge base of environmental and health impacts, public and expert perceptions, and geographic information that will characterize, quantify, and translate the recent wildfire and drought events into a coherent understanding of the region's drought and wildfire vulnerability and the community's response to it. This study is the first to gauge the perceived impacts of the drought and wildfire events in 2016. The results of this study contribute to a body of work exploring perceptions of water vulnerability, while also providing insight about events in western North Carolina, an understudied region in drought and wildfire literature.

\section{Methods}

\section{a. Site selection}

Buncombe and Watauga Counties in western North Carolina, selected as the two study sites, contain regionally dominant urban areas: Asheville and Boone, respectively (Fig. 1). Both sites offered a large pool of potential informants, making them ideal for gauging stakeholder perceptions of natural hazards. According to the 2017 American Community Survey (U.S. Census Bureau 2017), Buncombe County has a population of approximately 257000 , as compared with approximately 55000 in Watauga. Both counties are growing, with Buncombe experiencing a population growth rate of $8.1 \%$ and Watauga experiencing a growth rate of $7.9 \%$ from 2010 to 2017. The population is predominantly white in Buncombe (89.5\%) and Watauga (95.0\%), and both counties have younger populations with higher educational attainment relative to the populations of surrounding counties, due in part to the presence of the University of North Carolina at Asheville (Buncombe) and Appalachian State University (Watauga). The population continues to grow across the region and is projected to increase by $12 \%$ regionally between 2010 


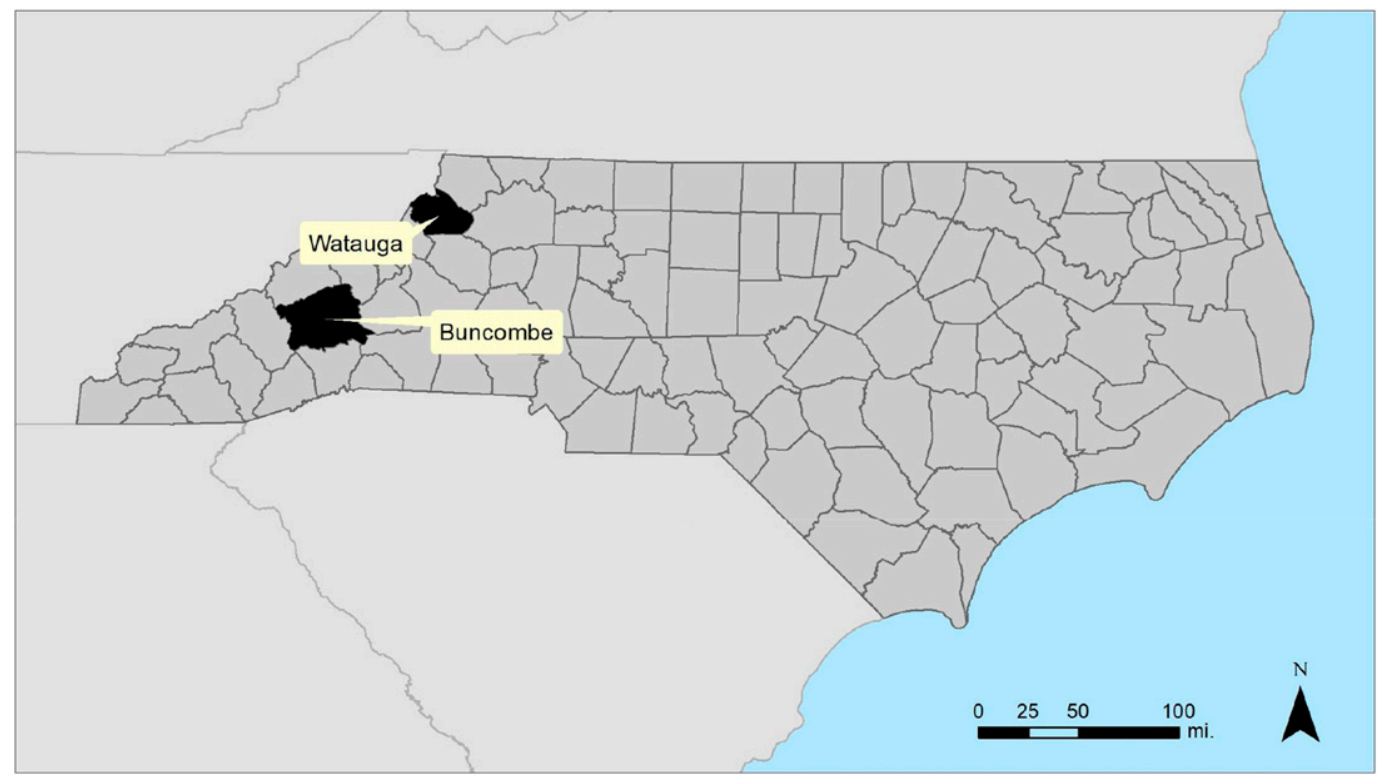

FIG. 1. Study sites.

and 2030 (NC Office of State Budget and Management 2017). The projected growth trend is especially pronounced in Buncombe County $(27 \%)$ and Watauga County $(40 \%)$. Growth is particularly high for elderly populations, a segment more vulnerable to climaterelated changes in water resources (NEMAC 2016). In Buncombe County, $19.1 \%$ of the population is 65 years or older, compared to the national average of $15.2 \%$ (U.S. Census Bureau 2017).

Buncombe and Watauga vary substantially in economic measures. The median household income is higher in Buncombe $(\$ 46,902)$ than Watauga $(\$ 39,443)$. Similarly, the poverty level is higher in Watauga $(24.3 \%)$ than in Buncombe (13.5\%). Differences between the two counties can be attributed in part to the differing sizes of the city of Asheville and the much smaller town of Boone. Despite these differences, the two counties have similarities that make them ideal for comparing experiences and perceptions relating to the events in 2016. These similarities include mountain geographies, growing economies, large tourism and hospitality sectors, and the presence of municipal, county, and natural resources agencies with knowledgeable staff.

Buncombe and Watauga Counties both experienced the effects of the drought and wildfires in 2016. The southwestern portion of western North Carolina entered abnormally dry conditions in late March 2016. The drought worsened throughout the year, peaking in late November 2016 with all of western North Carolina experiencing moderate, severe, or extreme drought (NC Drought Management Advisory Council 2018). As a result of the dry conditions, wildfires began throughout the southeastern United States in October. Approximately 39 fires occurred in late 2016 in western North Carolina. Both Buncombe and Watauga experienced large wildfires near popular tourist attractions, which had the potential to mimic the devastating Chimney Tops 2 fire in Gatlinburg, Tennessee. In November, the nearly 8000-acre Party Rock fire bordering Buncombe County led to evacuations in nearby Lake Lure and the town of Chimney Rock, and the nearly 1500-acre Horton Fire in Watauga County threatened the town of Blowing Rock (GeoMAC 2018). The events in 2016 were unprecedented for western North Carolina, but projected increases in drought and wildfire frequency combined with a growing population developing in the wildland-urban interface-the line, area, or zone in which structures and other human development meet or intermingle with undeveloped wildland or vegetative fuels-suggest elevated risk from water-related hazards (USFS 2018).

\section{b. Key informant interviews}

The objective of the study was to gauge regional perceptions of drought and wildfire among knowledgeable stakeholders through the collection and analysis of qualitative data in the form of interviews with key informants whose work is involved with or affected by water resources. Understanding of stakeholder perceptions can be used to inform mitigation policies, develop educational initiatives, and identify scientific gaps in the future. Initial lists of informants knowledgeable about 
drought and wildfire were compiled for Buncombe and Watauga Counties from the research team's professional networks and from publicly available material about water-relevant agencies, companies, and organizations. Additional informants were added to the lists using a snowball recruiting technique that was based on suggestions by initial informants. The key informants came from a variety of backgrounds, including emergency, safety, and fire (ESF); health systems (HS); local government and planning (LGP); nongovernmental organizations (NGO); private sector (PS); resource agencies (RA); state and federal agencies (SFA); and universities and schools (US).

A semistructured interview instrument consisting of 10 questions was created and reviewed by the Appalachian State University Institutional Review Board (IRB No.17-0219). The instrument was divided into two primary sections focusing on either water supply and drought or wildfire and air quality (Fig. 2).

Informants were recruited for the study through e-mail. A total of 29 informants-12 from Buncombe and 17 from Watauga-agreed to participate in an interview. The sector with the highest representation was SFA (with seven), and the sector with the lowest was NGO (with two) (Table 1).

Interviews with informants lasted approximately 20-30 min and were conducted by pairs of team members by telephone throughout the spring and summer of 2017. To ensure accuracy, each interview was recorded on two recording devices and then transcribed by one team member and reviewed for accuracy by another.

\section{c. Content analysis}

Preliminary analysis of the transcripts yielded general lists of nominal classifications, or "codes," for each county that are based on themes that emerged from the interviews. The lists were later combined and refined into an initial coding dictionary consisting of seven code groups with 84 codes. The coding dictionary and interview transcripts were loaded into "Atlas.ti 8," a software that enables systematic analysis of qualitative data, for content analysis. According to Krippendorff (2004), content analysis is defined as "a research technique for making replicable and valid inferences from texts (or other meaningful matter) to the contexts of their use." This method has previously been used to identify patterns in interview responses (e.g., Combs et al. 2016; McNeeley et al. 2016).

The interview transcripts were reviewed, and fragments of the transcripts were assigned codes from the coding dictionary. Additional codes were added individually by team members during active coding as appropriate. Each transcript was double coded by two different team members. Then, all coding of transcripts was reviewed and reconciled by one team member. For duplicate codes with differing quotation lengths, the reconciler chose to utilize the more extensive choice or to create a new, larger quotation for the code. The average number of codes assigned to a transcript was 106. The reconciled transcripts were analyzed to determine major themes. A word cloud and corresponding code frequency table were produced to identify commonly used codes. Matrices were produced to compare code occurrence by sector and county, as well as to illustrate and summarize code co-occurrences.

\section{Results and discussion}

\section{a. Main themes}

During the coding process, 19 free codes were added to the 84 predetermined codes in the dictionary, resulting in a total of 103 codes. The codes were categorized into seven code groups, which are general labels used to categorize related codes and can be considered major themes throughout the interviews (these codes and code groups will be capitalized hereinafter). The largest number of codes was associated with Natural Resources and Environment (25), followed by Policy and Governance (19), Education and Communication (18), Human Health (13), Economics (11), Emergency Response (9), and Community (8). The codes were used a total of 3077 times. The most frequently used codes were Water Management (168) and Public Awareness (158). Table 2 shows the 25 most commonly occurring codes, all of which appeared in the content analysis at least 50 times. The frequency counts inevitably reflect the interview instrument itself (with questions containing the key words), as well as the dominance of various terms used by interviewees.

Notably, many of the most frequently used codes were directly associated with Emergency Response in relation to the wildfires, including Firefighters, Fire Management, and Fire Suppression, and with health impacts from the wildfires, including Air Quality, Smoke Exposure, and Respiratory, indicating the wildfires were a dominant concern for key informants in western North Carolina. Additionally, many of the frequently used codes were associated with knowledge dissemination, either relating to Education and Communication (e.g., Public Awareness, Intra-Agency, and Data Sharing) or Policy and Governance (e.g., Research and Data). Only one predetermined code-Population Growth-was not used, and related terms, such as Tourism, Seasonal Residents, and New Residents, were used only four times each. This demonstrates an apparent low level of concern about the influence of new and temporary residents on drought and wildfire hazard in western 
For the first part of this interview, we are going to ask you some questions about water supply and drought:

1. How is water supply relevant to your job - what do you have to consider and think about regarding water? a. Does drought impact your work?

2. What is the process for making water management decisions in your community or business during a drought (key players, citizen involvement, downstream users, county, data used, communication, etc.)?

3. If the service area / community's water supply was threatened, how would you find out?

a. Do you feel like you're receiving adequate information?

b. If not, what type of information would you like to receive?

4. There was a drought in the Southeast in 2016 . How did the drought affect your job (impacts, new policies, etc.)?

a. How did the drought impact the local service population / community?

For the second part of this interview, we are going to ask you some questions about wildfires and air quality:

5. There were significant wildfires in the Southeast in the fall of 2016. How did these wildfires affect your community (impacts, new policies, etc.)?

6. How did the wildfires and resulting poor air quality affect your service population's / community's health?

7. Do you supervise workers who spend a portion or all of their workday outdoors?

a. If so, how did the wildfires and resulting poor air quality affect these workers?

8. How do you inform the service population / community about drought and/or wildfire events?

a. What challenges do you face when you are disseminating information to your service population / the public?

b. Are there specific communication challenges in the high country given the large area and rural/urban differences?

9. Has your recent experience with drought and wildfire events altered your approach to your work?

10. Do you have any other comments or insights you would like to share with us?

a. Is there anyone else you think we should talk with?

Thank you for your time and expertise. We will now stop the recording.

FIG. 2. Key-informant interview questions.

North Carolina and aligns with Cockerill (2014), who found that over one-third of decision-makers were "not at all concerned" about the potential for population growth to reduce water availability.

A word cloud illustrates the most frequently used words in coded quotations (Fig. 3). As with the frequency counts, word clouds naturally reflect not only content from the interviews but also the interview instrument itself. That is, among the most frequently used words were those relating to the questions asked, such as "water," "drought," and "fire," and knowledge-related words, such as "know," "think," and "information." Other frequently used words related to the themes of people, community, and health.

\section{b. Contextual variations in findings}

Matrices were produced to compare coding results between sectors and counties. As expected, the importance

TABLE 1. Number of survey participants by key-informant sector and county.

\begin{tabular}{lrcc}
\hline \multicolumn{1}{c}{ Sector } & All & Buncombe & Watauga \\
\hline Emergency, safety, and fire & 4 & 1 & 3 \\
Health systems & 3 & 1 & 2 \\
Local government or planning & 4 & 2 & 2 \\
Nongovernmental organizations & 2 & 1 & 1 \\
Private sector & 4 & 1 & 3 \\
Resource agencies & 2 & 1 & 1 \\
State and federal agencies & 7 & 3 & 4 \\
Universities and schools & 3 & 2 & 1 \\
Total & 29 & 12 & 17 \\
\hline
\end{tabular}

of themes varied by sector and county. Figure 4 reveals variation in the frequency of code groups across professional sectors and between the two counties. Both Natural Resources and Environment and Education and Communication appeared as important themes across nearly all professional sectors, as well as in both counties. In contrast, codes relating to Community and Economics were cited much less frequently.

Other themes showed more variation. In some cases, informants most frequently discussed topics relating to their profession. For example, Policy and Governance codes were most dominant among informants from LGP (27.5\% of codes), Education and Communication codes were most dominant among informants from US $(26.6 \%$ of codes), and Emergency Response codes were most dominant among informants from ESF $(22.5 \%$ of codes). In other cases, informants most frequently discussed topics indirectly relating to their profession. For example, Education and Communication codes were most dominant among informants from HS $36.5 \%$ of codes), as compared with Human Health codes (22.4\% of codes).

Figure 5 provides more detail and shows the 25 most common individual codes and their frequency variation across professional sectors and between the two counties. The finer resolution of individual codes reveals greater variation among professional sectors when compared with the general, thematic code groups. Similar to the code-group results, Education and Communication codes (including Public Awareness, Intra-Agency, Data Sharing, Response, Disaster Severity, Traditional 
TABLE 2 . The codes that correspond to the most frequently used content.

\begin{tabular}{|c|c|c|}
\hline Code & Code group & Count \\
\hline Water Management & Natural Resources and Environment & 168 \\
\hline Public Awareness & Education and Communication & 158 \\
\hline Disaster Severity & Natural Resources and Environment & 115 \\
\hline Air Quality & Human Health & 110 \\
\hline Firefighters & Emergency Response & 98 \\
\hline Smoke Exposure & Human Health & 97 \\
\hline Intra-Agency & Education and Communication & 95 \\
\hline Data Sharing & Education and Communication & 88 \\
\hline Response & Education and Communication & 80 \\
\hline Response & Policy and Governance & 77 \\
\hline Resources & Emergency Response & 75 \\
\hline Research & Policy and Governance & 72 \\
\hline Agriculture/Farming & Natural Resources and Environment & 69 \\
\hline Disaster Severity & Education and Communication & 66 \\
\hline Traditional Media & Education and Communication & 63 \\
\hline Technology & Education and Communication & 62 \\
\hline Data & Policy and Governance & 59 \\
\hline Fire Management & Emergency Response & 56 \\
\hline Agriculture/Farming & Economics & 55 \\
\hline Fire Suppression & Emergency Response & 55 \\
\hline Water Consumption & Policy and Governance & 55 \\
\hline Resources & Policy and Governance & 54 \\
\hline Disaster Severity & Human Health & 53 \\
\hline Forestry & Natural Resources and Environment & 51 \\
\hline Respiratory & Human Health & 50 \\
\hline
\end{tabular}

Media, and Technology) and Natural Resources and Environment codes (including Water Management, Disaster Severity, Agriculture/Farming, and Forestry) were frequently used across professional sectors.
Also similar to the code-group results, informants often discussed themes directly related to their professional sector. For example, $13.2 \%$ of the codes from informants from RA related to Agriculture/Farming,

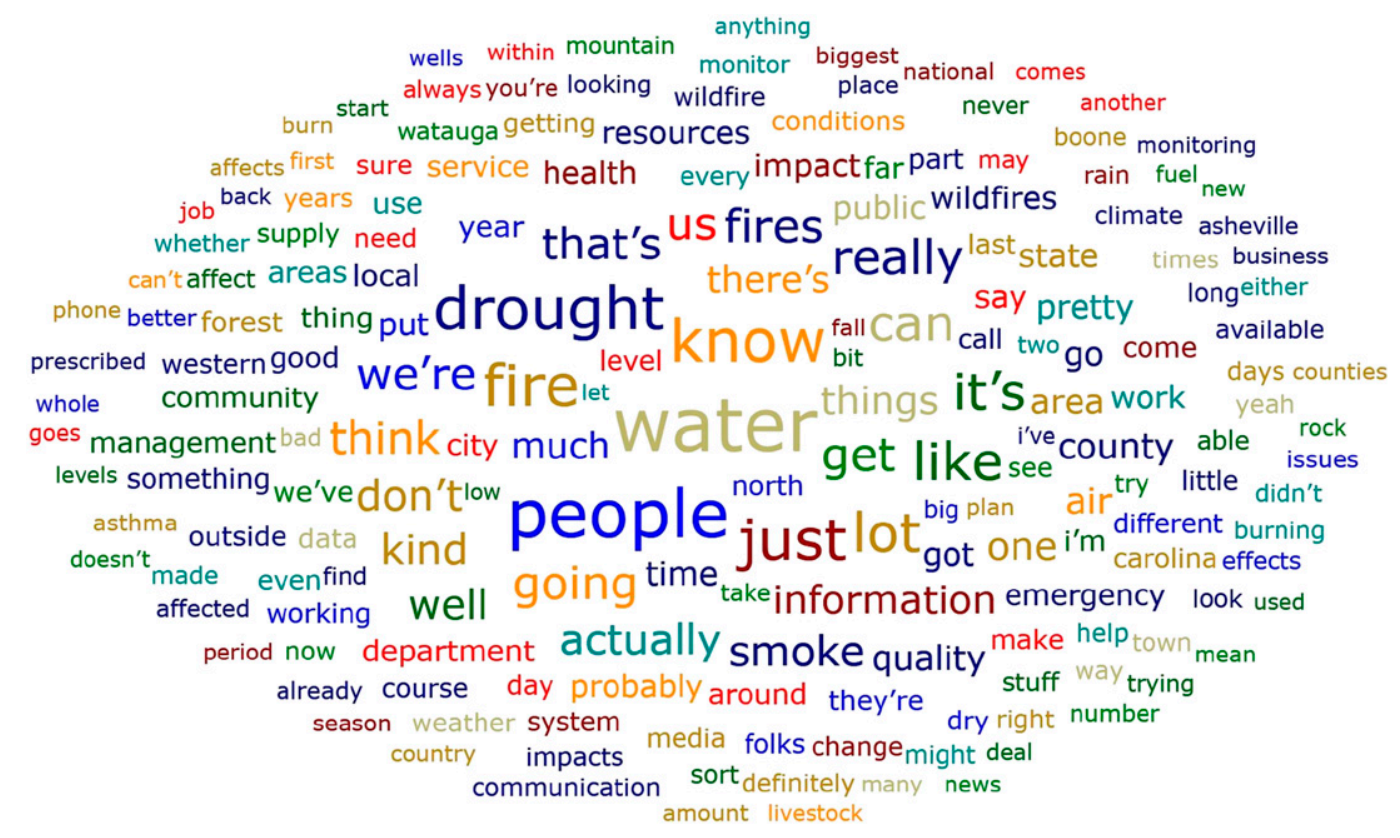

FIG. 3. Word cloud for all coded text. 


\begin{tabular}{|c|c|c|c|c|c|c|c|c|c|c|}
\hline \multirow{2}{*}{ Code Group } & \multicolumn{7}{|c|}{ Sector } & \multicolumn{2}{c|}{ County } \\
\cline { 2 - 10 } & ESF & HS & LGP & NGO & PS & RA & SFA & US & B & W \\
\hline Community & $5.3 \%$ & $2.9 \%$ & $6.6 \%$ & $3.0 \%$ & $7.3 \%$ & $2.2 \%$ & $4.8 \%$ & $0.8 \%$ & $7.3 \%$ & $3.6 \%$ \\
\hline Economics & $5.9 \%$ & $1.8 \%$ & $4.5 \%$ & $9.0 \%$ & $22.2 \%$ & $11.1 \%$ & $2.8 \%$ & $0.8 \%$ & $6.3 \%$ & $7.5 \%$ \\
\hline Education and Communication & $18.2 \%$ & $\mathbf{3 6 . 5} \%$ & $22.1 \%$ & $28.4 \%$ & $21.5 \%$ & $33.3 \%$ & $19.2 \%$ & $\mathbf{2 6 . 6} \%$ & $20.9 \%$ & $\mathbf{2 3 . 7} \%$ \\
\hline Emergency Response & $\mathbf{2 2 . 5} \%$ & $7.1 \%$ & $3.7 \%$ & $6.0 \%$ & $1.0 \%$ & $3.0 \%$ & $10.4 \%$ & $4.8 \%$ & $5.9 \%$ & $11.9 \%$ \\
\hline Human Health & $7.0 \%$ & $22.4 \%$ & $11.9 \%$ & $11.9 \%$ & $11.3 \%$ & $4.4 \%$ & $14.2 \%$ & $23.4 \%$ & $15.1 \%$ & $10.8 \%$ \\
\hline Natural Resources and Environment & $20.9 \%$ & $13.5 \%$ & $23.8 \%$ & $\mathbf{4 1 . 8} \%$ & $\mathbf{3 2 . 1} \%$ & $\mathbf{3 4 . 8} \%$ & $\mathbf{2 8 . 1} \%$ & $25.0 \%$ & $\mathbf{3 0 . 5} \%$ & $23.7 \%$ \\
\hline Policy and Governance & $20.2 \%$ & $15.9 \%$ & $\mathbf{2 7 . 5} \%$ & $0.0 \%$ & $4.6 \%$ & $11.1 \%$ & $20.5 \%$ & $18.5 \%$ & $13.8 \%$ & $18.9 \%$ \\
\hline
\end{tabular}

FIG. 4. Matrix of code-group dominance by sector and county.

$10.4 \%$ of codes from ESF informants related to Firefighters, and $10.2 \%$ of codes from LGP informants related to Water Management. However, HS informants more frequently discussed topics relating to the Education and Communication theme, primarily Public Awareness (5.4\% of codes) and Response (5.4\% of codes), instead of topics relating to Human Health. This trend may partially be explained by new action among community health workers to improve health literacy and prevent adverse health outcomes through targeted public health interventions and warning campaigns (USDHHS 2010).

Informants from NGO most frequently discussed Public Awareness (9.2\% of codes), informants from PS most frequently discussed Water Management (8.1\% of codes), informants from SFA most frequently discussed Response relating to Policy and Governance $(6.6 \%$ of codes), and informants from US most frequently discussed Response relating to Education and Communication (5.9\% of codes) and Forestry (5.9\% of codes).

In both counties, informants most frequently discussed topics relating to Water Management and Public Awareness. In Buncombe County, $7.0 \%$ of codes related to Water Management, followed by $5.9 \%$ relating to Public Awareness. In Watauga County, $4.8 \%$ of codes related to Public Awareness and $4.6 \%$ of codes related to Water Management. Notable differences between the two counties include the Firefighters code, which was much more frequently reported in Watauga $(4.0 \%$ of codes) than in Buncombe County (1.6\% of codes), and Disaster Severity, which occurred much more frequently in Buncombe (5.1\% of codes) than in Watauga County
(3.0\% of codes). Buncombe County key informants appeared to have greater concern about natural resources, while those in Watauga County appeared to have greater concern about emergency response.

A code co-occurrence matrix was created to analyze codes that were frequently mentioned together (Fig. 6). Notable combinations included

- Smoke Exposure and Air Quality (88),

- Water Management and Water Consumption (52),

- Intra-Agency and Data Sharing (51), and

- Response and Public Awareness (50).

In addition to Air Quality, Smoke Exposure was frequently used along with other health-related codes like Respiratory, Disaster Severity, Vulnerable Populations, Outdoor Workers, and Asthma. The majority of concerns about wildfire appeared to be associated with respiratory health impacts. Media reports of respiratory illness confirm health concerns driven by diminished air quality with multiple locations, including Chattanooga, Tennessee; Knoxville, Tennessee; and Spartanburg, South Carolina, reporting increases in respiratory patients. Yet, a pilot analysis of emergency department data in western North Carolina found no significant increases in asthma, acute bronchitis, and chronic obstructive pulmonary disease during the 1-week period surrounding the poor air quality events (Konrad and Knox 2017). The pilot work emphasizes the challenges with linking health impacts to short-term wildfire smoke exposure and potential mismatch between perceived health risks and quantifiable health impacts. 


\begin{tabular}{|c|c|c|c|c|c|c|c|c|c|c|}
\hline \multirow{2}{*}{ Code } & \multicolumn{8}{|c|}{ Sector } & \multicolumn{2}{|c|}{ County } \\
\hline & ESF & HS & LGP & NGO & PS & RA & SFA & US & B & $\mathbf{w}$ \\
\hline Water Management & $4.5 \%$ & $5.1 \%$ & $10.2 \%$ & $4.6 \%$ & $8.1 \%$ & $5.4 \%$ & $3.8 \%$ & $2.2 \%$ & $7.0 \%$ & $4.6 \%$ \\
\hline Public Awareness & $3.0 \%$ & $5.4 \%$ & $3.8 \%$ & $9.2 \%$ & $7.2 \%$ & $7.8 \%$ & $5.5 \%$ & $4.8 \%$ & $5.8 \%$ & $4.8 \%$ \\
\hline $\begin{array}{l}\text { Disaster Severity (Natural } \\
\text { Resources and Environment) }\end{array}$ & $3.2 \%$ & $2.7 \%$ & $2.2 \%$ & $5.7 \%$ & $6.0 \%$ & $2.4 \%$ & $4.2 \%$ & $3.8 \%$ & $5.1 \%$ & $3.0 \%$ \\
\hline Air Quality & $2.4 \%$ & $4.7 \%$ & $3.0 \%$ & $3.4 \%$ & $4.2 \%$ & $0.5 \%$ & $4.7 \%$ & $5.4 \%$ & $4.5 \%$ & $3.0 \%$ \\
\hline Firefighters & $10.4 \%$ & $0.0 \%$ & $0.5 \%$ & $0.0 \%$ & $0.0 \%$ & $0.0 \%$ & $2.2 \%$ & $0.0 \%$ & $1.6 \%$ & $4.0 \%$ \\
\hline Smoke Exposure & $2.2 \%$ & $2.3 \%$ & $2.2 \%$ & $3.4 \%$ & $5.1 \%$ & $0.5 \%$ & $4.2 \%$ & $3.8 \%$ & $4.3 \%$ & $2.5 \%$ \\
\hline Intra-Agency & $3.7 \%$ & $5.1 \%$ & $5.5 \%$ & $1.1 \%$ & $1.2 \%$ & $2.4 \%$ & $2.2 \%$ & $3.2 \%$ & $2.9 \%$ & $3.2 \%$ \\
\hline Data Sharing & $3.3 \%$ & $1.2 \%$ & $2.5 \%$ & $0.0 \%$ & $2.1 \%$ & $6.3 \%$ & $3.6 \%$ & $0.5 \%$ & $2.5 \%$ & $3.1 \%$ \\
\hline $\begin{array}{c}\text { Response (Education and } \\
\text { Communication) }\end{array}$ & $0.8 \%$ & $5.4 \%$ & $1.4 \%$ & $6.9 \%$ & $1.2 \%$ & $7.3 \%$ & $2.3 \%$ & $5.9 \%$ & $2.3 \%$ & $2.8 \%$ \\
\hline $\begin{array}{l}\text { Response (Policy and } \\
\text { Governance) }\end{array}$ & $3.5 \%$ & $3.9 \%$ & $4.9 \%$ & $0.0 \%$ & $0.0 \%$ & $2.4 \%$ & $1.6 \%$ & $2.2 \%$ & $2.3 \%$ & $2.6 \%$ \\
\hline Resources (Emergency Response) & $5.3 \%$ & $3.9 \%$ & $1.1 \%$ & $0.0 \%$ & $0.5 \%$ & $0.5 \%$ & $1.5 \%$ & $3.2 \%$ & $1.5 \%$ & $3.0 \%$ \\
\hline Research & $0.1 \%$ & $0.4 \%$ & $2.5 \%$ & $0.0 \%$ & $0.0 \%$ & $2.0 \%$ & $6.6 \%$ & $2.7 \%$ & $2.6 \%$ & $2.2 \%$ \\
\hline $\begin{array}{l}\text { Agriculture/Farming (Natural } \\
\text { Resources and Environment) }\end{array}$ & $0.7 \%$ & $0.0 \%$ & $0.3 \%$ & $1.1 \%$ & $7.7 \%$ & $13.2 \%$ & $0.3 \%$ & $0.0 \%$ & $1.5 \%$ & $2.7 \%$ \\
\hline $\begin{array}{c}\text { Disaster Severity (Education and } \\
\text { Communication) }\end{array}$ & $1.8 \%$ & $0.0 \%$ & $2.5 \%$ & $4.6 \%$ & $2.8 \%$ & $3.4 \%$ & $2.0 \%$ & $2.2 \%$ & $2.3 \%$ & $2.1 \%$ \\
\hline Traditional Media & $0.5 \%$ & $3.5 \%$ & $2.2 \%$ & $3.4 \%$ & $3.0 \%$ & $2.0 \%$ & $1.6 \%$ & $4.8 \%$ & $2.9 \%$ & $1.6 \%$ \\
\hline Technology & $2.9 \%$ & $1.9 \%$ & $2.2 \%$ & $1.1 \%$ & $2.8 \%$ & $0.5 \%$ & $1.3 \%$ & $1.6 \%$ & $0.9 \%$ & $2.6 \%$ \\
\hline Data & $2.4 \%$ & $0.8 \%$ & $0.8 \%$ & $0.0 \%$ & $1.9 \%$ & $2.4 \%$ & $2.8 \%$ & $0.5 \%$ & $0.8 \%$ & $2.5 \%$ \\
\hline Fire Management & $4.3 \%$ & $0.8 \%$ & $0.8 \%$ & $1.1 \%$ & $0.2 \%$ & $0.5 \%$ & $1.9 \%$ & $0.0 \%$ & $0.7 \%$ & $2.4 \%$ \\
\hline Agriculture/Farming (Economics) & $1.1 \%$ & $0.0 \%$ & $0.3 \%$ & $1.1 \%$ & $6.5 \%$ & $7.3 \%$ & $0.3 \%$ & $0.0 \%$ & $0.5 \%$ & $2.5 \%$ \\
\hline Fire Suppression & $3.8 \%$ & $0.4 \%$ & $0.8 \%$ & $2.3 \%$ & $0.0 \%$ & $0.0 \%$ & $2.5 \%$ & $0.0 \%$ & $0.9 \%$ & $2.3 \%$ \\
\hline Water Consumption & $2.4 \%$ & $1.9 \%$ & $4.1 \%$ & $0.0 \%$ & $0.5 \%$ & $1.0 \%$ & $1.3 \%$ & $1.6 \%$ & $1.9 \%$ & $1.7 \%$ \\
\hline $\begin{array}{l}\text { Resources (Policy and } \\
\text { Governance) }\end{array}$ & $2.5 \%$ & $1.9 \%$ & $2.7 \%$ & $0.0 \%$ & $0.5 \%$ & $0.5 \%$ & $1.5 \%$ & $2.7 \%$ & $1.5 \%$ & $1.9 \%$ \\
\hline Disaster Severity (Human Health) & $1.3 \%$ & $4.3 \%$ & $1.6 \%$ & $4.6 \%$ & $0.7 \%$ & $0.5 \%$ & $2.0 \%$ & $1.1 \%$ & $2.2 \%$ & $1.5 \%$ \\
\hline Forestry & $0.7 \%$ & $0.0 \%$ & $0.0 \%$ & $0.0 \%$ & $0.0 \%$ & $0.0 \%$ & $4.4 \%$ & $5.9 \%$ & $1.1 \%$ & $2.0 \%$ \\
\hline Respiratory & $0.9 \%$ & $3.5 \%$ & $1.1 \%$ & $2.3 \%$ & $1.6 \%$ & $1.5 \%$ & $1.5 \%$ & $3.2 \%$ & $1.5 \%$ & $1.7 \%$ \\
\hline
\end{tabular}

FIG. 5. Matrix of code dominance by sector and county for the most common codes. 


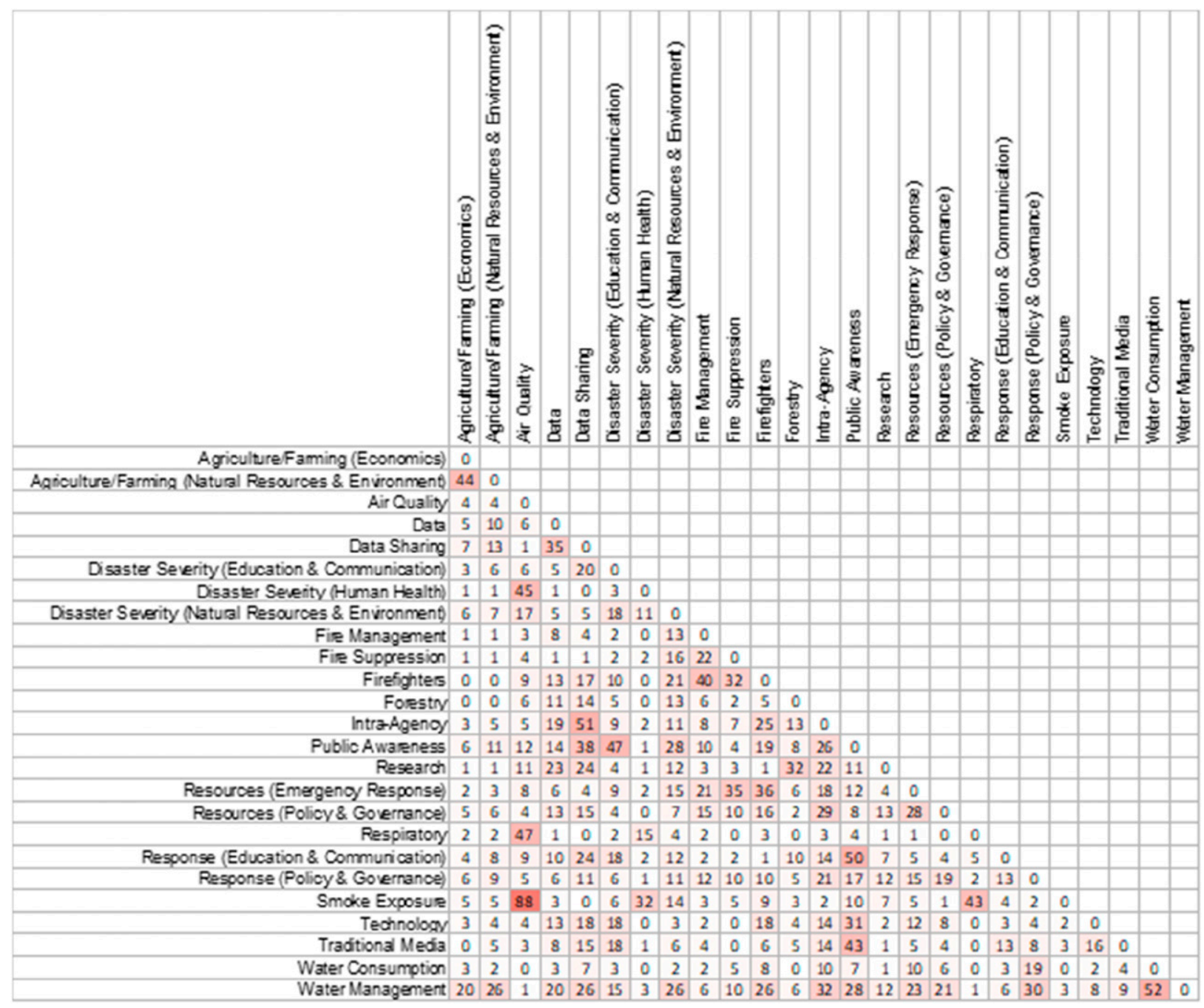

FIG. 6. Matrix of code co-occurrence for the most common codes.

In addition to Water Consumption, Water Management was frequently used along with Intra-Agency, Response, Public Awareness, Disaster Severity, Firefighters, Agriculture/Farming, Conservation, and Resources, indicating pressing concerns about water quantity among informants.

Codes related to Education and Communication and Policy and Governance frequently occurred with one another. Intra-Agency was frequently used along with codes relating to dissemination, such as Data Sharing, Public Awareness, Research, Decision-Making, and Data. Similarly, Public Awareness was frequently used along with codes like Response, Traditional Media, Technology, Word of Mouth, and Social Media. This result indicates that decision-makers are communicating with one another, as well as striving to educate the public. These frequent co-occurrences highlight relationships among codes that may suggest important themes that merit deeper exploration and may inform future work in this area.

Interviews with key informants revealed several notable trends. Natural Resources and Environment was the most frequent theme among responses, indicating the majority of concerns about water-related hazards were related to impacts to the landscape. Many informants focused on disaster severity and indicated the region was not anticipating the severity of the drought and wildfire events in 2016. Additionally, many informants discussed how the drought and wildfires affected resources, particularly forestry and agriculture.

Overall, informants were more knowledgeable about the wildfires than the drought, and they frequently discussed emergency responses and health impacts associated with the wildfire outbreak in 2016. Informants were 
particularly concerned with the impacts of diminished air quality on vulnerable populations, including outdoor workers, firefighters, and the elderly. One outdoor worker stated, "In 22, 23 years, I've never seen so many wildfires. It's horrible, it's horrible...we are outside working 10 to 12 hours a day and all these weather people, weather applications, and stuff are like, 'Air quality is low. If you don't have to be outside you should stay inside.'. . that's not an option for us." Additionally, many informants expressed concern about water management, specifically water quantity, and the importance of water for agriculture and firefighting. This concern about water management is in contrast to Cockerill et al. (2014), who found low concerns about water management among decision-makers in western North Carolina. This finding suggests that concerns about water supply may have been heightened in the wake of the extreme events in 2016.

Education and Communication was frequently discussed by informants, often in the context of their sector of expertise. Education and Communication codes were often used in conjunction with Policy and Governance codes. Informants emphasized the lack of public knowledge regarding water-related hazards, which suggested that past events may be viewed by many as a rare occurrence instead of a sign of change. Informants from HS discussed themes relating to Education and Communication more than themes relating to Human Health, highlighting the key role of knowledge dissemination in public health responses during hazardous events (USDHHS 2010). Increasing public awareness, especially through the use of social media, appeared to be a priority for key informants across all sectors. Informants alluded to communication challenges in the region and frequently cited "word of mouth" as an information dissemination technique. One informant explained, "Just talking with folks as we see them around in the rural areas. Word of mouth is a great way for us to do that, but there are definitely some challenges because not everyone has the capability to have access to the Internet or television." Discussions with informants highlighted a well-developed intra-agency communication network with frequent data sharing, as well as attempts to strengthen collaboration following the events in 2016. In Watauga County, for example, one informant spoke about the role a newly developed intra-agency group of Public Information Officers (PIOs) played during the wildfires, saying, "The fact that we had this relationship and we knew who the other PIOs were, we had just started meeting about the time of the Horton Fire, but we now have gelled...we have a great collaborative of public information officers from a cross section of organizations across the community." Organizations directly involved in response are using the recent events as a learning experience moving forward.

Surprisingly, informants less frequently discussed themes relating to Community and Economics. Since the objective of the interviews was to gain professional insight about the events in 2016, key informants were less likely to discuss community characteristics. Of the codes relating to Community, Vulnerability was used most frequently. During the drought and wildfires in 2016, local communities were particularly vulnerable, perhaps due to Education and Communication challenges driven by rural settlement. Because interview questions did not specifically address economic topics, key informants were less likely to discuss economic topics. Several codes relating to Economics, including Agriculture/Farming, Financial Impacts, and Disaster Frequency, were used more frequently, suggesting concerns about the impacts of drought and wildfire on the agricultural industry. Additionally, key informants involved in emergency management and fire suppression discussed the high costs associated with emergency management resources, particularly overtime pay, during the wildfires. Informants rarely mentioned the growth of both permanent and temporary populations or development in the wildland-urban interface, despite these themes being associated with drought and wildfire risk in scientific literature. This may reflect these circumstances being viewed as background conditions under which key informants conduct their work.

Some informants discussed increases in the frequency of hazardous events. One stated, "It just seems like drought has been a way of life here for the last couple years. I hope we can kind of get out of that mode here soon." Others discussed the future. One informant said, "I think there is going to be a lot more of that with the changing climate and typically drier, particular drier late summer and fall, and an increased likelihood of fire." However, interviews with informants revealed differing opinions about climate change itself. While some informants saw the events as an opportunity for change, others doubted the need for such changes. One informant said, "There is some change, there's been change...we have seen more dry climate situations in our area, so going forward. . .it will take some fires and some losses for us to have a culture change, which is what is going to change those local policies and...regulation and that sort of thing." Another informant expressed, "We have sort of a brief opening here that we have people's ear about fire and climate change." In contrast, one informant stated, "It's easy for people to sit back nowadays and say, 'Well, all these changes that the earth is going through right now and the reason we have forest fires and the reason we have droughts and the reason it's so 
hot, all this stuff, is because of humans,' and I'm sure that some of that stuff is true, but I don't think it's fair to make humans suffer to try to combat mother nature and time." This difference of opinions further complicates policymaking. However, several informants noted how western North Carolina lacks the more stringent preparedness and mitigation policies present in the western portion of the United States, indicating an awareness that better policies are needed.

The informant feedback reveals regionwide prioritization of Natural Resources and Environment and Education and Communication, and the translation of concerns about these themes to policy changes following the events in 2016. However, responses also demonstrate subtle variations in thought regionally (between the east and west) and by county (between Buncombe and Watauga), which are likely the result of differences in landscapes, demographics, resources, policies, and exposure to water-related hazards. These findings highlight the complexities of developing a coordinated mitigation response to natural hazards across a region with variations in size, economies, and governance.

\section{Conclusions}

In 2016, an exceptional drought and subsequent wildfires devastated the southeastern United States. In the future, water-related hazards could threaten the Southeast more frequently, indicating a need for better understanding of stakeholder perceptions of drought and wildfire to strengthen mitigation policies. To gain better understanding of the events in 2016, the team conducted interviews with key informants from Buncombe and Watauga Counties in western North Carolina and analyzed the results in Atlas.ti. Informant feedback demonstrates how experiences and perceptions about hazards vary by profession and location, but also reflect common regional concerns about natural resources and public awareness. The findings indicate stakeholders recognized the severity of the drought and wildfires in 2016 and, as a result, increased their communication with one another and the public. However, the responses also reveal a lack of concern about the drivers of such hazards, which could hinder the establishment of effective policies to address future risk.

The study, using qualitative methods, had some limitations. Although measures were taken to reduce bias from the study by employing a semistructured interview instruments and using two coders and an additional reconciler, coding remains an art that involves some personal judgments. Time constraints limited the number of interviews that could be conducted, and certain sectors are better represented than others. Finally, this study focused on two of the most populated counties and, therefore, is not representative of the entirety of western North Carolina. The purpose of this study was to broadly analyze trends in two counties. Additional work will be needed to gauge water-relevant experiences and perceptions at larger scales.

The analysis of key-informant experiences and perceptions contributes to a larger research need for understanding of public experiences and perceptions of water vulnerability, particularly in the southeastern United States. A public survey would enhance the depth of the study by providing a bottom-up perspective of the drought and wildfires in 2016 and supporting additional work on messaging and community-based social marketing relating to water vulnerability and public health in western North Carolina. Additionally, quantitative assessments of vulnerability to natural hazards are needed to complement qualitative analyses, such as the present study, and identify specific locations of interest.

Ultimately, the findings provide insights for researchers and practitioners interested in enhancing public awareness about hazards. The key informants identified several areas that would benefit from future research, particularly regarding risk communication and effective messaging for a region with significant communication challenges. In the future, this work would benefit from collaboration, with researchers fostering relationships with critical individuals and agencies such as the participants in this study. Last, effective communication of the results to both the public and policymakers will be crucial for empowering and protecting communities in western North Carolina.

Acknowledgments. The authors thank the following students for support with preliminary analysis: C. Allred, J. Bunce, T. Karlson, A. Mosunova, J. Kimball, N. O'Reilly, A. Parks, and A. Sumrow. This project was supported by a grant from the Research Institute for Environment, Energy, and Economics at Appalachian State University.

\section{REFERENCES}

Archie, K. M., 2014: Mountain communities and climate change adaptation: Barriers to planning and hurdles to implementation in the Southern Rocky Mountain Region of North America. Mitigation Adapt. Strategies Global Change, 19, 569-587, https://doi.org/10.1007/s11027-013-9449-z.

Brody, S. D., S. Zahran, A. Vedlitz, and H. Grover, 2008: Examining the relationship between physical vulnerability and public perceptions of global climate change in the United States. Environ. Behav., 40, 72-95, https://doi.org/10.1177/ 0013916506298800.

Burstein, P., 2010: Public opinion, public policy, and democracy. Handbook of Politics: State and Society in Global Perspective, K. T. Leicht and J. C. Jenkins, Eds., Springer, 63-79.

Cockerill, K., 2010: Communicating how water works: Results from a community water education program. J. Environ. Educ., $\mathbf{4 1}$, 151-164, https://doi.org/10.1080/00958960903295266. 
_ 2014: The water supply is fine: Decision-maker perceptions of water quantity and supply-side management. Water Environ. J., 28, 242-251, https://doi.org/10.1111/wej.12029.

_ C. Badurek, and R. Hale, 2014: Managing water in western North Carolina: Decision-maker perceptions and policy implementation. Environ. Pract., 16, 94-101, https://doi.org/ 10.1017/S1466046614000015.

Combs, T. S., E. Shay, D. Salvesen, C. Kolosna, and M. Madeley, 2016: Understanding the multiple dimensions of transportation disadvantage: The case of rural North Carolina. Case Stud. Transp. Policy, 4, 68-77, https://doi.org/10.1016/j.cstp.2016.02.004.

Diggs, D., 1991: Drought experience and perception of climatic change among Great Plains farmers. Great Plains Res., 1, 114-132.

Dow, K., R. E. O' Connor, B. Yarnal, G. J. Carbone, and C. L. Jocoy, 2007: Why worry? Community water system managers' perceptions of climate vulnerability. Global Environ. Change, 17, 228-237, https://doi.org/10.1016/j.gloenvcha.2006.08.003.

Frei, A., R. L. Armstrong, M. P. Clark, and M. C. Serreze, 2002: Catskill Mountain water resources: Vulnerability, hydroclimatology, and climate-change sensitivity. Ann. Assoc. Amer. Geogr., 92, 203-224, https://doi.org/10.1111/1467-8306.00287.

GeoMAC, 2018: GeoMAC services. U.S. Department of the Interior, accessed 1 June 2018, https://www.geomac.gov/services.shtml.

Hamilton, L. C., and B. D. Keim, 2009: Regional variation in perceptions about climate change. Int. J. Climatol., 29, 23482352, https://doi.org/10.1002/joc.1930.

IPCC, 2013: Summary for policymakers. Climate Change 2013: The Physical Science Basis. T. F. Stocker et al., Eds., Cambridge University Press, 1-29.

Kenny, J. F., N. L. Barber, S. S. Hutson, K. S. Linsey, J. K. Lovelace, and M. A. Maupin, 2009: Estimated use of water in the United States in 2005. U.S. Geological Survey Circular 1344, 52 pp., http://pubs.usgs.gov/circ/1344.

Konrad, C. E., and P. Knox, 2017: The southeastern drought and wildfires of 2016. NIDIS Rep., 85 pp., https://sercc.com/ NIDISDroughtAssessmentFINAL.pdf.

Krippendorff, K., 2004: Content Analysis: An Introduction to Its Methodology. SAGE Publications, $456 \mathrm{pp}$.

Manabe, S., R. T. Wetherald, P. C. D. Milly, T. L. Delworth, and R. J. Stouffer, 2004: Century-scale change in water availability: $\mathrm{CO}_{2}$-quadrupling experiment. Climatic Change, 64, 59-76, https://doi.org/10.1023/B:CLIM.0000024674.37725.ca.

McNeeley, S. M., T. A. Beeton, and D. S. Ojima, 2016: Drought risk and adaptation in the interior United States: Understanding the importance of local context for resource management in times of drought. Wea. Climate Soc., 8, 147-161, https://doi.org/ 10.1175/WCAS-D-15-0042.1.

NC Drought Management Advisory Council, 2018: Drought monitor archive: US drought monitor of North Carolina. North Carolina Drought Management Advisory Council, accessed 1 June 2018, http://www.ncdrought.org/archive/.

NCEI, 2017: Drought for annual 2016. NOAA National Centers for Environmental Information, accessed 1 June 2018, https:// www.ncdc.noaa.gov/sotc/drought/201613\#se-sect.

_ 2018a: Definition of drought. NOAA National Centers for Environmental Information, https://www.ncdc.noaa.gov/monitoringreferences/dyk/drought-definition.

_ 2018b: Billion-dollar weather and climate disasters: Summary stats. NOAA National Centers for Environmental Information, accessed 1 June 2018, https://www.ncdc.noaa.gov/billions/ summary-stats.

NC Office of State Budget and Management, 2017: County/state population projections. North Carolina State Office of State
Budget and Management, accessed 1 June 2018, https://www. osbm.nc.gov/demog/county-projections.

NEMAC, 2016: Western North Carolina vitality index: Historical population trends. North Carolina State Office of State Budget and Management, accessed 1 June 2018, http://www. wncvitalityindex.org/population/historical-population-trends.

O'Gorman, P. A., and T. Schneider, 2009: The physical basis for increases in precipitation extremes in simulations of 21st-century climate change. Proc. Natl. Acad. Sci. USA, 106, 14 773-14 777, https://doi.org/10.1073/pnas.0907610106.

PRISM Climate Group, 2018: 30-year normal precipitation: Annual. PRISM Climate Group, accessed 1 June 2018, http:// www.prism.oregonstate.edu/normals/.

Responsive Management, 2003: Understanding the Georgia public's perception of water issues and the motivational messages to which they will respond: Focus group findings. Responsive Management Rep., 17 pp., https://cfpub.epa.gov/npstbx/files/GAwaterFG.pdf.

Roy, S. B., L. Chen, E. H. Girvetz, E. P. Maurer, W. B. Mills, and T. M. Grieb, 2012: Projecting water withdrawal and supply for future decade in the U.S. under climate change scenarios. Environ. Sci. Technol., 46, 2545-2556, https://doi.org/10.1021/es2030774.

Saarinen, T. F., 1966: Perception of the drought hazard on the Great Plains. University of Chicago Dept. of Geography Research Paper 106, 183 pp.

Seager, R., A. Tzanova, and J. Nakamura, 2009: Drought in the southeastern United States: Causes, variability over the last millennium, and the potential for future hydroclimate change. J. Climate, 22, 5021-5045, https://doi.org/10.1175/2009JCLI2683.1.

Spence, A., W. Poortinga, C. Butler, and N. F. Pidgeon, 2011: Perceptions of climate change and willingness to save energy related to flood experience. Nat. Climate Change, 1, 46-49, https://doi.org/10.1038/nclimate1059.

Taylor, J. G., T. R. Stewart, and M. Downton, 1988: Perceptions of drought in the Ogallala Aquifer region. Environ. Behav., 20, 150-175, https://doi.org/10.1177/0013916588202002.

U.S. Census Bureau, 2000: Census 2000 summary file 1 (SF 1) 100-percent data, table P001: Total population. American FactFinder, accessed 1 June 2018, https://factfinder.census.gov/ faces/tableservices/jsf/pages/productview.xhtml?pid $=$ DEC $_{-}$ 00_SF1_P001\&prodType $=$ table .

_ 2 2010: 2010 Census summary file 1, table P001: Total population. American FactFinder, accessed 1 June 2018, https://factfinder. census.gov/faces/tableservices/jsf/pages/productview.xhtml?pid= DEC_00_SF1_P001\&prodType $=$ table

, 2017: QuickFacts: United States. U.S. Census Bureau, accessed 1 June 2018, https://www.census.gov/quickfacts/fact/map.

USDHHS, 2010: National action plan to improve health literacy. U.S. Department of Health and Human Services Rep., 73 pp., https://health.gov/communication/HLActionPlan/ pdf/Health_Literacy_Action_Plan.pdf.

USFS, 2018: Fire terminology. National Park Service/USDA Forest Service, https://www.fs.fed.us/nwacfire/home/terminology.html.

USGCRP, 2016: The impacts of climate change of human health in the United States: A scientific assessment. U.S. Global Change Research Program Rep., 312 pp., https://doi.org/10.7930/J0R49NQX.

Vörösmarty, C. J., P. Green, J. Salisbury, and R. B. Lammers, 2000: Global water resources: Vulnerability from climate change and population growth. Science, $\mathbf{2 8 9}, 284-288$, https://doi.org/ 10.1126/science.289.5477.284.

Woudenberg, D., D. A. Wilhite, and M. Hayes, 2008: Perception of drought hazard and its sociological impacts in south-central Nebraska. Great Plains Res., 18, 93-102. 